
\title{
25 Research Soure \\ The Anxiolytic effect of salicylic acid is mediated via the GABAergic system
}

Sahel Motaghi ( $\nabla$ sahelmotaghi@gmail.com )

Shahid Bahonar University of Kerman https://orcid.org/0000-0002-2159-6195

Hadi Moghaddam Dizaj Herik

Shahid Bahonar University of Kerman

Gholamreza Sepehri

Kerman Neuroscience Research Center

Mehdi Abbasnejad

Shahid Bahonar University of Kerman

Saeed esmaeli-Mahani

Shahid Bahonar University of Kerman

\section{Research Article}

Keywords: Salicylic acid, Anxiety, Glutamate decarboxylase, Hippocampus

Posted Date: July 31st, 2021

DOI: https://doi.org/10.21203/rs.3.rs-704957/v1

License: (1) This work is licensed under a Creative Commons Attribution 4.0 International License.

Read Full License 


\section{Abstract}

Salicylic acid (SA) is a natural phenolic compound in plants with many beneficial effects for humans. The anxiolytic effect of this compound has been reported in animal models, but its mechanism of action remains unclear. In this study, by using the fear potentiated plus maze test, we evaluated the effect of salicylic acid on the gene expression of the main form of GABA synthesizing enzyme i.e., the enzyme glutamic acid decarboxylase 67 (GAD67), in the ventral subiculum of the hippocampus. Also, the hypnotic effect of Salicylic acid was evaluated. Animals were divided into the solvent, (SA) and diazepam treated groups $(n=6)$. For evaluating the anxiolytic effect of Salicylic acid, animals were subjected to 2 hours of isolation, before placing them in the elevated plus maze (EPM). Afterward, the ventral part of the hippocampus was removed for evaluating the change in (GAD67) gene expression by the reverse transcription-quantitative polymerase chain reaction (RTqPCR) technique. The hypnotic effect of Salicylic acid was evaluated in the ketamine induced sleeping test. Our results showed that Salicylic acid at 10, 30 $(\mathrm{mg} / \mathrm{kg})$ increased time spent and entries to the open arms in the (EPM) $(p<0.05)$. (RTqPCR) revealed that $30 \mathrm{mg} / \mathrm{kg}$ of Salicylic acid increased (GAD67) gene expression $(p<0.001)$. Salicylic acid (30 and 300 $\mathrm{mg} / \mathrm{kg})$ also increased the duration of sleep, in ketamine induced sleeping test $(p<0.05)$. Our results showed that Salicylic acid has anxiolytic and hypnotic effects and it exerts its anxiolytic effect partly, via up regulation of (GAD67) in the ventral part of the hippocampus.

\section{Declarations}

\section{Funding}

This research is financially supported by the Neuroscience Research Center, Kerman University of Medical Sciences with the grant (\#98/24)

\section{Compliance with ethical standards}

Ethical approval The procedure of this experiment was based on the ethical principles of international committees that protect laboratory animals (Approval No. IR.KMU.REC. 1399. 096).

Conflict of interest The authors declare that there is no conflict of interest.

Data Availability Statement The data that support the findings of this study are available from the corresponding author upon reasonable request.

Author contributions Sahel Motaghi designed the experiment, analyzed the data and prepared the manuscript. Gholamreza Sepehri made scientific aid in all the procedures of the experiments and also preparing the manuscript. Hadi Moghaddam Dizaj Herik did the experiment. Mehdi Abbasnejad supervised on behavioral study and related statical analysis. Saeed esmaeli-Mahani supervised on molecular study. All authors read and approved the final manuscript.

There is no consent to participate and no consent to publish. 


\section{Acknowledgments}

This research is financially supported by the Neuroscience Research Center, Kerman University of Medical Sciences with the grant (\#98/24)

\section{Introduction}

Anxiety is the state of high arousal and enhanced vigilance in the absence of an immediate threat. This state is useful sometimes because helps survival by increasing awareness and rapid responses to a possible hazard, but if it occurs persistently or disproportionately can be debilitating and so, is considered pathological (Davis et al. 2010; Calhoon and Tye 2015). The prevalence of anxiety disorders is estimated to be $18 \%$ among adults with a lifetime prevalence of more than $28 \%$ (Kessler et al 2005). So, finding new drugs with the least side effects has long been a challenge. Abnormalities in the GABAergic system in the brain, cause anxiety disorders (Green et al. 2020; Felice et al. 2020). GABA is an inhibitory neurotransmitter in the CNS and is made by the enzyme glutamic acid decarboxylase (GAD). Studies in mammals and plants encountered stress conditions show the elevation in cytosolic $\mathrm{Ca} 2+$ and thus the subsequent activation of (GAD). In both mammals and plants, GABA plays an important role against stress conditions (Fromm 2020). Salicylic acid (SA) is another molecule secreted in plants and plays an important role in defense against a broad spectrum of different stressors (Lu et al. 2016). Studies also show the efficacy of this compound in treating anxiety and insomnia in animal models (Khan et al. 2015; Langstieh et al. 2014). Numerous studies show the efficacy of nutraceuticals and herbal medicines in the treatment of anxiety and stress (Srivastava and Kumar 2021).

In mammals, there are two forms of (GAD) in the brain, including (GAD67) and (GAD65), which are products of two independently regulated genes i.e., (GAD1) and (GAD2) respectively. Almost all of (GAD67) is in its active form, while much of the (GAD65) is inactive and acts as a reserve pool (Martin and Rimvall 1993). The ventral part of the hippocampus (vCA1) is enriched in anxiety cells that are activated by anxiogenic environments and are required for avoidance behavior. (Jimenez et al. 2018). Acute stress preferentially increases (GAD67) in the hippocampus, but chronic stress preferentially upregulates the expression of (GAD65) in other regions of anxiety circuits (Bowers et al. 1998). Considering the similarity in $\mathrm{Ca} 2+$ dependent mechanism of GABA action in animals and plant tissues in stress conditions, it seems reasonable that there would a relationship between (SA) and (GAD). In this regard, Bauer et al. 2000 showed that chronic administration of SA increased (GAD65) expression in the brain (Bauer al. 2000). In the field of anxiety, the elevated plus maze is one of the most popular animal models (Carobrez and Bertoglio 2005; Biedermann et al. 2017). Fear in this model can be potentiated by a prior inescapable stressor exposure such as predator odor, isolation, swim stress, social defeat, etc. It is called fear potentiated plus maze behavior and reflects an enhanced anxiety state. In contrast to traditional plus maze testing, the results of this animal model are very robust and this model is also sensitive to anxiolytics and anxiogenics which act via the GABAergic system (Korte et al, 2003). As there are no reports about the effect of salicylic acid on (GAD) in anxiety disorders, in this study by using the fear potentiated plus maze behavior with the prior stressor isolation, we evaluated the effect of this 
phenolic compound on the expression of (GAD67), the main form of (GAD) in the ventral part of the hippocampus.

\section{Materials And Methods}

\section{Animals}

Male Wistar rats weighing 180-220 were purchased from the animal house of Shahid Bahonar University of Kerman. They were housed under $12 \mathrm{~h}$ light/dark cycle and at $22 \pm 2^{\circ} \mathrm{C}$ temperature and were ad libitum for food and water intakes. For adapting to the new environment, the experiments were done after one week. All experiments were reviewed and approved by the animal ethical committee of the Shahid Bahonar University of Kerman (Approval No. IR.KMU.REC. 1399. 096), which complies with the ARRIVE guidelines (Kilkenny et al. 2010).

\section{Drugs}

Salicylic acid (Molekula, England), Ketamine hydrochloride (Bremer Pharma GMBH, Germany), and diazepam (Caspian Pharmaceutical Co, Iran) were used in this study. For diluting (SA), it was dissolved in DMSO and alcohol and then diluted with normal saline. The ratio of normal saline to DMSO and alcohol was $(3: 1: 1)(\mathrm{v} / \mathrm{v})$.

\section{Experimental design to evaluate the anxiolytic effect of salicylic acid}

Animals were randomly divided into seven groups $(n=6)$. The Control group received the solvent, and the 5 salicylic acid treated groups were injected with $0.1,1,10,30$, and $300 \mathrm{mg} / \mathrm{kg}$ of it. The name of each group was according to the dose received. One group received diazepam $(3 \mathrm{mg} / \mathrm{kg})$ as the reference drug. The drugs were administered intraperitoneally (i.p) $30 \mathrm{~min}$ before placing the rats in the elevated plus maze. All rats were suffered from 2 hours of isolation before placing in the maze (fear potentiated plus maze test). It should be mentioned that rats were transferred and habituated to the testing room for $24 \mathrm{~h}$ before the test.

\section{Elevated plus maze}

Elevated plus maze is a method for the measurement of anxiety in rodents. It is consisted of two open arms $(50 \mathrm{~cm} \times 10 \mathrm{~cm} \times 2.5 \mathrm{~cm})$ and two closed arms $(50 \mathrm{~cm} \times 10 \mathrm{~cm} \times 20 \mathrm{~cm})$, extending from a central platform $(10 \mathrm{~cm} \times 10 \mathrm{~cm})$. The open arms are perpendicular to the closed ones. The central square and the arms are located $50 \mathrm{~cm}$ above the floor. Rats were placed individually on the center of the maze, facing to open arms and then allowed to explore freely for 5 min (Lister 1987; Pellow et al. 1985). The 


\section{Experimental design to evaluate the hypnotic effect of salicylic acid}

Ketamine (100 mg/kg, i.p.) was used to induce sleep in rats (Douglas and Dagirmanjian 1975). Rats in different groups $(n=6)$ were pre-treated with the solvent, salicylic acid with 3 different doses of $(10,30,300$ $\mathrm{mg} / \mathrm{kg}$ ), and diazepam (3 mg/kg), $30 \mathrm{~min}$ before the administration of ketamine. Each animal was observed for sleep latency (SL) or the onset of sleep (time from injection of ketamine to time of loss of righting reflex) and the duration of sleep or total sleeping time (TST) i.e., the time from loss to regain of consciousness.

\section{Experimental design for detecting the effect of salicylic acid on hippocampal GAD67 gene expression in the fear potentiated plus maze test}

After fear potentiated plus maze test animals were euthanized in a CO2 chamber. The ventral part of the hippocampus from each rat brain, were dissected and transferred to the liquid nitrogen and then stored in a $-80^{\circ} \mathrm{C}$ freezer. All the control, diazepam, and also the specimens from the SA treated groups which showed the anxiolytic effects, were chosen for evaluating (GAD67) gene expression with the reverse transcription-quantitative polymerase chain reaction technique $(n=6)$.

\section{Reverse transcription-quantitative polymerase chain reaction (RTqPCR)}

Total RNA from each group was extracted with an RNA isolation kit (DENAzist Asia, Iran). The quantity of total RNA was calculated with a NanoDrop spectrophotometer (Thermo Scientific, USA) and agarose gel electrophoresis. The RNA templates were used for cDNA synthetizing by adding random hexamer and dNTP mix according to the manufacturing company (Pars tous, Iran). QPCR master mix (Pars tous, Iran) were added and prepared for PCR running with SYBR green reporter dye. Samples were run three times on PCR light cycler Roche (Roche life Science, Germany) and the gene expression data were analyzed via its software version 1.1. The program of the real time apparatus for the genes was: $95^{\circ} \mathrm{C}$ for 8 min followed by 40 cycles of $95^{\circ} \mathrm{C}$ for $30 \mathrm{~s}, 60^{\circ} \mathrm{C}$ for $30 \mathrm{~s}$, and $72^{\circ} \mathrm{C}$ for $30 \mathrm{~s}$. Samples were normalized with the housekeeping gene glyceraldehyde-3-phosphate dehydrogenase (GAPDH). The sequences of primers used are as follows: GAD67: forward CACAGAGACGGACTTCTCCA; reverse AACTGCACAGTTTGCTCCTC, GAPDH: forward CAAGGCTGAGAATGGGAAGC; reverse GAAGACGCCAGTAGACTCCA. 
To determine the relative gene expression ratio, the $\Delta \Delta C T$ mathematical model was applied, and 2- $\Delta \Delta C T$ was carried out for statistical analysis of relative gene expression (Schmittgen and Livak 2008).

\section{Statistical Analysis}

The behavioral tests and the RTqPCR dataset were analyzed by SPSS statistics 26 software (Chicago, USA) and the significant differences between groups of the study were detected by one-way analysis of variance (ANOVA) followed by the Duncan's post hoc test. All data were presented as mean \pm SEM and values of $p<0.05$ were considered statistically significant.

\section{Results}

\section{Effect of salicylic acid on anxiety behavior in the elevated plus maze}

Figure 1 shows the effects of salicylic acid on the elevated plus maze parameters. As shown in Fig. 1 A and $B$, in comparison to the control group, salicylic acid at 10 and $30 \mathrm{mg} / \mathrm{kg}$ enhanced open arm entries $(p<0.05$ and $p<0.01$ respectively) and also open arm time spent $(p<0.05)$. These effects showed a dose-dependent manner $(p<0.01)$. Diazepam significantly increased open arm time spent more than other groups (Fig 1B).

\section{Sedative and hypnotic activity of salicylic acid on the ketamine-induced hypnosis test}

The onset of sleep decreased in animals that received diazepam and $30 \mathrm{mg} / \mathrm{kg}$ of salicylic acid $(p<$ 0.05). The effect of salicylic acid at $10 \mathrm{mg} / \mathrm{kg}$ on sleep latency was significantly less than diazepam and the dose of $30 \mathrm{mg} / \mathrm{kg}$ of salicylic acid $(p<0.05$ ) (Fig. 2A). Total sleeping time or sleep duration prolonged in animals treated with the diazepam $(p<0.01), 30 \mathrm{mg} / \mathrm{kg}$ and $300 \mathrm{mg} / \mathrm{kg}$ of salicylic acid $(p<0.05)$. as shown in Fig. 2B, the effect of the groups which received diazepam and $300 \mathrm{mg} / \mathrm{kg}$ of salicylic acid, on total sleeping time, was more than the group treated with $10 \mathrm{mg} / \mathrm{kg}$ of salicylic acid $(p<0.05)$

\section{Effect of salicylic acid on hippocampal GAD67 gene expression in the fear potentiated plus maze test}

As shown in Figure 3, the expression of (GAD67) increased in the ventral part of the hippocampus in animals treated with $30 \mathrm{mg} / \mathrm{kg}$ of salicylic acid $(p<0.001)$. Diazepam decreased the expression of this enzyme $(p<0.001)$ 
The expression of this enzyme was significantly lower in $10 \mathrm{mg} / \mathrm{kg}$ treated groups compared to the group which received $30 \mathrm{mg} / \mathrm{kg}$ salicylic acid $(p<0.001)$.

\section{Discussion}

Our result showed that salicylic acid or 2- hydroxybenzoic acid reduced anxiety in a dose dependent manner. It also potentiated the duration of sleep induced by ketamine administration. Structurally diverse hydroxybenzoic acid derivatives such as 2 -,3- and 4- hydroxybenzoic acid are bioactive constituents of many edible and medicinal plants and are involved in their beneficial effects (Manuja et al. 2013; TomásBarberán and Clifford 2000). 2- hydroxybenzoic acid or salicylic acid, is also the main metabolite of aspirin (acetylsalicylic acid). Similar to our results, the anxiolytic effect of salicylic acid and other mono hydroxybenzoic acids had been shown. Khan et al. 2015., showed that chronic and oral administration of salicylic acid $(20 \mathrm{mg} / \mathrm{kg})$ and aspirin $(20 \mathrm{mg} / \mathrm{kg})$ for 11 days had diazepam anxiolytic effects in the elevated plus maze. They also reported that aspirin and all of the hydroxybenzoic acids (including 2-, 3and 4-hydroxy benzoic acids) reduced the hyperthermia induced by foot-shock stress. Despite our study, they showed that just higher doses of aspirin and 3-hydroxy benzoic acid (above $30 \mathrm{mg} / \mathrm{kg}$ ), increased the duration of sleep induced by pentobarbitone. In the mentioned study they evaluated the effect of chronic and low dose $(20 \mathrm{mg} / \mathrm{kg})$ of salicylic acid and 4-hydroxybenzoic acids on onset and duration of sleep (Khan et al 2015). So, the difference seen between our and their results may be related to the dosage and route of administration. In another study by Longstieh et al. 2014 reported that the hyperthermia induced by foot-shock stress was reduced by acute administration of a high and single dose of salicylic acid $(300 \mathrm{mg} / \mathrm{kg})$. Despite the study by Khan et al. 2015, these authors reported that chronic administration of salicylic acid $(30,100,300 \mathrm{mg} / \mathrm{kg})$ shortened the onset of sleep and prolonged its duration in the pentobarbitone induced sleep test (Longstieh et al. 2014). We observed the acute and high dose of salicylic acid $(300 \mathrm{mg} / \mathrm{kg})$ prolonged the duration of sleep induced by ketamine but not pentobarbitone. So, these different results can be attributed to the different kinds of sleeping induced tests and also the type of administration i.e. single but not repetitive injection. In recent studies by Winne et al. 2019 and 2020, acute administration of salicylic acid $(300 \mathrm{mg} / \mathrm{kg}$, IP) induced anxiety like behavior in mice. They showed that anxiety and tinnitus had strong comorbidity and suggested that salicylate inducing anxiety behavior is due to the acute generation of tinnitus (Winne et al. 2019 \& 2020). Salicylate can generate tinnitus in both humans and animals (Eggermont and Roberts 2015). It shows that the effective dose of salicylic acid for its anxiolytic effects should be taken into consideration more cautiously.

In this study, we used a state anxiety model, which means that animals are exposed to a stressful condition before placing in the elevated plus maze. We chose this model because, in contrast to the plus maze test that measures innate fear of open and high places, this model reflects an enhanced anxiety mood. (Korte and Boer 2003). Physiological responses to stress are triggered by glucocorticoid hormones. The release of glucocorticoids is initiated from hypothalamic paraventricular neurons (PVN) which promote the release of adrenocorticotrophic hormone (ACTH) and subsequently glucocorticoids. Efficient inhibition of glucocorticoids limits the magnitude and duration of stress at the level of the PVN, 
which is acquired by both central inhibitory circuits and negative feedback by glucocorticoids in the blood (Bowers et al. 1998). The ventral part of the hippocampus is one of the main structures which inhibit the HPA axis. It had been shown that lesions of the ventral subiculum of the hippocampus decreased corticotropin releasing factor (CRF) mRNA expression and stress duration (Herman et al 1995). $\mathrm{Y}^{-}$ Aminobutyric acid (GABA), the major inhibitory neurotransmitter in the CNS, regulates a variety of biological functions in the brain. GABA is synthesized from glutamate by glutamic acid decarboxylase (GAD) which has two isoforms with different molecular weights, $67 \mathrm{kDa}$ (GAD67) and $65 \mathrm{kDa}$ (GAD65). Bowers et al. 1998 reported that there is a preferential upregulation of GAD in the brain circuits responsible for direct control of HPA like the hypothalamus and hippocampus. These authors showed that chronic stress induced (GAD65) mRNA expression whereas acute stress selectively increased (GAD67) mRNA in the hypothalamus and hippocampus. In a recent study, it was also shown that the loss of (Gad67) function, altered conditioned fear behavior in adult rats (Fujihara et al. 2020). As we were assessing an acute anxiety model, we evaluated the effect of salicylic acid on (GAD 67) but not (GAD65) expression. However, Makinson et al. 2015 showed that chronic social subordination stress increased the (GAD67) mRNA level in the hippocampus (Makinson et al. 2015). So, it seems reasonable to investigate the effect of salicylic acid on (GAD 65) expression too. Other studies show the effects of phytochemicals on (GAD) too. For example, Ku et al. 2011 showed that chronic administration of honokiol, an active agent extracted from Magnolia bark Officinalis, caused anxiolytic action by increasing the protein level of (GAD65). In our study diazepam as an anxiolytic agent decreased the (Gad67) mRNA level compared to control and salicylic acid treated groups. Ku et al. 2015 also reported that in diazepam treated groups the protein level of (GAD65) was significantly lower than the honokiol treated animals (Ku et al. 2015). These data show that diazepam may have inhibitory effects on Gad67 gene expression. Studies show that benzodiazepines such as diazepam exert their pharmacological effects through allosteric modulation of $\mathrm{GABA}_{\mathrm{A}}$ receptors to facilitate GABAergic synaptic transmission. Specifically, the allosteric binding within the limbic system leads to the anxiolytic effects seen with diazepam (Friedman et al. 1992). So, the anxiolytic effect of diazepam is related to its effect on the $\mathrm{GABA}_{A}$ receptors. It seems that the long-term administration, unwanted side effects of benzodiazepines, such as tolerance and physical dependence is due to $\mathrm{GABA}_{A}$ receptor desensitization (Haelphy 1988), so these adverse side effects should not be seen by using the drugs which act on GABA synthesizing enzyme or (GAD). In this regard, it had been shown that long-term administration of honokiol an anxiolytic phytochemical which exerts its effect via increasing (GAD65) did not elicit the mentioned side effects (Maruyama et al. 1998).

In conclusion, this study shows that salicylic acid exerts its anxiolytic via (GAD67) upregulation in the ventral part of the hippocampus and affecting the synthesis of GABA. This mechanism of action suggests that there may be less harmful effects, but, as salicylic acid can produce tinnitus, more detailed studies about its effective dose and also the mechanism of action are required.

\section{References}


1. Bauer CA, Brozoski TJ, Holder TM, Caspary DM (2000) Effects of chronic salicylate on GABAergic activity in rat inferior colliculus. Hear Res 147:175 - 82. / 10.1016/s0378-5955(00)00130-1

2. Biedermann SV, Biedermann DG, Wenzlaff F, Kurjak T, Nouri S, Auer MK, Wiedemann K, Briken P, Haaker J, Lonsdorf TB, Fuss J (2017) An elevated plus-maze in mixed reality for studying human anxiety-related behavior. BMC biol 15:1-3. https://doi.org /10.1186/s12915-017-0463-6

3. Bowers G, Cullinan WE, Herman JP (1998) Region-specific regulation of glutamic acid decarboxylase (GAD) mRNA expression in central stress circuits. J Neurosci 18:5938-5947. https://doi.org /10.1523/JNEUROSCI.18-15-05938.1998

4. Calhoon GG, Tye KM (2015) Resolving the neural circuits of anxiety. Nat Neurosci 2015 18:1394 404. https://doi.org/10.1038/nn.4101

5. Carobrez AP, Bertoglio LJ (2005) Ethological and temporal analyses of anxiety-like behavior: the elevated plus-maze model 20 years on. Neurosci Biobehav Rev 29:1193-1205. / 10.1016/j.neubiorev.2005.04.017

6. Davis M, Walker DL, Miles L, Grillon C (2010) Phasic vs sustained fear in rats and humans: role of the extended amygdala in fear vs anxiety. Neuropsychopharmacology 35:105-135. https://doi.org/10.1038/npp.2009.109

7. Douglas BG, Dagirmanjian R (1975) The effects of magnesium deficiency on ketamine sleeping times in the rat. BJA: Br J Anaesth 47:336-340. https://doi.org /10.1093/bja/47.3.336

8. Eggermont JJ, Roberts LE (2105) Tinnitus: animal models and findings in humans. Cell Tissue Res 361311-361336. https://doi.org/10.1007/s00441-014-1992-8

9. Felice D, Cryan JF, O'Leary OF (2020) GABAB Receptors: Anxiety and Mood Disorders. In: In: Curr Top Behav Neurosci. Springer, Berlin, pp 1-25. https://doi.org/10.1007/7854_2020_171 0

10. Friedman H, Greenblatt DJ, Peters GR, Metzler CM, Charlton MD, Harmatz JS, Antal EJ, Sanborn EC, Francom SF (1992) Pharmacokinetics and pharmacodynamics of oral diazepam: effect of dose, plasma concentration, and time. Clin Pharmacol Ther 52:139-150. https://doi.org/10.1016/j.phymed.2011.03.007

11. Fromm H (2020) GABA signaling in plants: Targeting the missing pieces of the puzzle. J Exp Bot 71:6238-6245. https://doi.org/ 10.1093/jxb/eraa358

12. Fujihara K, Sato T, Miyasaka Y, Mashimo T, Yanagawa Y (2020) Genetic deletion of the 67-kDa isoform of glutamate decarboxylase alters conditioned fear behavior in rats. FEBS Open bio 11:340353. https://doi.org/10.1002/2211-5463.13065

13. Green TA, Baracz SJ, Everett NA, Robinson KJ, Cornish JL (2020) Differential effects of GABA A receptor activation in the prelimbic and orbitofrontal cortices on anxiety. Psychopharmacology 237:3237-3247. https://doi.org/10.1007/s00213-020-05606-9

14. Haefely WE (1988) Benzodiazepines. Int Anesthesiol Clin 26:262 - 72. https://doi.org/10.1097/00004311-198802640-00005

15. Herman JP, Cullinan WE, Morano MI, Akil H, Watson SJ (1995) Contribution of the ventral subiculum to inhibitory regulation of the hypothalamo-pituitary-adrenocortical axis. J Neuroendocrinol 7:475- 
482. https://doi.org/10.1111/j.1365-2826.1995.tb00784.x

16. Jimenez JC, Su K, Goldberg AR, Luna VM, Biane JS, Ordek G, Zhou P, Ong SK, Wright MA, Zweifel L, Paninski L (2018) Anxiety cells in a hippocampal-hypothalamic circuit. Neuron 97:670-683. https://doi.org /10.1016/j.neuron.2018.01.016

17. Kessler RC, Berglund P, Demler O, Jin R, Merikangas KR, Walters EE (2005) Lifetime prevalence and age-of-onset distributions of DSM-IV disorders in the National Comorbidity Survey Replication. Arch Gen Psychiatry 62:593-602. https://doi.org/10.1001/archpsyc.62.6.593

18. Khan SA, Chatterjee SS, Kumar V (2015) Potential anti-stress, anxiolytic and antidepressant like activities of mono-hydroxybenzoic acids and aspirin in rodents: a comparative study. Austin $\mathrm{J}$ Pharmacol Ther 3:1073-1083

19. Kilkenny C, Browne W, Cuthill IC, Emerson M, Altman DG (2010) Animal research: reporting in vivo experiments: the ARRIVE guidelines. Br J Pharmacol 160:1577-1579. https://doi.org /10.1111/j.1476-5381.2010.00872.x

20. Korte SM, De Boer SF (2003) A robust animal model of state anxiety: fear-potentiated behaviour in the elevated plus-maze. Eur J Pharmacol 463:163 - 75. https://doi.org /10.1016/s00142999(03)01279-2

21. Ku TH, Lee YJ, Wang SJ, Fan CH, Tien LT (2011) Effect of honokiol on activity of GAD65 and GAD67 in the cortex and hippocampus of mice. Phytomedicine 18:1126-1129. https://doi.org/10.1016/j.phymed.2011.03.007

22. Langstieh AJ, Verma P, Thakur AK, Chatterjee SS, Kumar V (2014) Desensitization of mild stress triggered responses in mice by a Brassica juncea leaf extract and some ubiquitous secondary plant metabolites. Pharmacologia 5:326-338

23. Lister RG (1987) The use of a plus-maze to measure anxiety in the mouse. Psychopharmacology 92:180-185. https://doi.org/ 10.1007/BF00177912

24. Lu H, Greenberg JT, Holuigue L (2016) Salicylic acid signaling networks. Front Plant Sci 7:238. https://doi.org/ 10.3389/fpls.2016.00238

25. Makinson R, Lundgren KH, Seroogy KB, Herman JP (2015) Chronic social subordination stress modulates glutamic acid decarboxylase (GAD) 67 mRNA expression in central stress circuits. Physiol Behav 146:7-15. https://doi.org/10.1016/j.physbeh.2015.04.025

26. Maruyama Y, Kuribara H, Morita M, Yuzurihara M, Weintraub ST (1998) Identification of magnolol and honokiol as anxiolytic agents in extracts of saiboku-to, an oriental herbal medicine. J Nat Prod 61:135-138. https://doi.org/10.1021/np9702446

27. Manuja R, Sachdeva S, Jain A, Chaudhary (2013) A comprehensive review on biological activities of p-hydroxy benzoic acid and its derivatives. Int J Pharm Sci Rev Res 22:109-115

28. Martin DL, Rimvall K (1993) Regulation of $y$-aminobutyric acid synthesis in the brain. J Neurochem 60:395-407. / 10.1111/j.1471-4159.1993.tb03165.x

29. Pellow S, Chopin P, File SE, Briley M (1985) Validation of open: closed arm entries in an elevated plusmaze as a measure of anxiety in the rat. J Neurosci Methods 14:149-167. https://doi.org 
/10.1016/0165-0270(85)90031-7

30. Schmittgen TD, Livak KJ (2008) Analyzing real-time PCR data by the comparative C T method. Nat Protoc 3:1101. / 10.1038/nprot.2008.73

31. Srivastava A, Kumar P (2021) Nutraceuticals in anxiety and stress. In: Nutraceuticals, 2nd edn., Academic Press. https://doi.org/10.1016/B978-0-12-821038-3.00004-5

32. Tomás-Barberán FA, Clifford MN (2000) Dietary hydroxybenzoic acid derivatives-nature, occurrence and dietary burden. J Sci Food Agric 80:1024-32. https://doi.org/10.1002/(SICI)10970010(20000515)80:7<1024::AID-JSFA567>3.0.C0;2-S

33. Winne J, Franzon R, de Miranda A, Malfatti T, Patriota J, Mikulovic S, Leão KE, Leão RN (2019) Salicylate induces anxiety-like behavior and slow theta oscillation and abolishes the relationship between running speed and fast theta oscillation frequency. Hippocampus 29:15-25. https://doi.org/10.1002/hipo.23021

34. Winne J, Boerner BC, Malfatti T, Brisa E, Doerl J, Nogueira I, Leão KE, Leão RN (2020) Anxiety-like behavior induced by salicylate depends on age and can be prevented by a single dose of 5-MeODMT. Exp Neurol 1:326:113175. https://doi.org/10.1016/j.expneurol.2020.113175

\section{Figures}



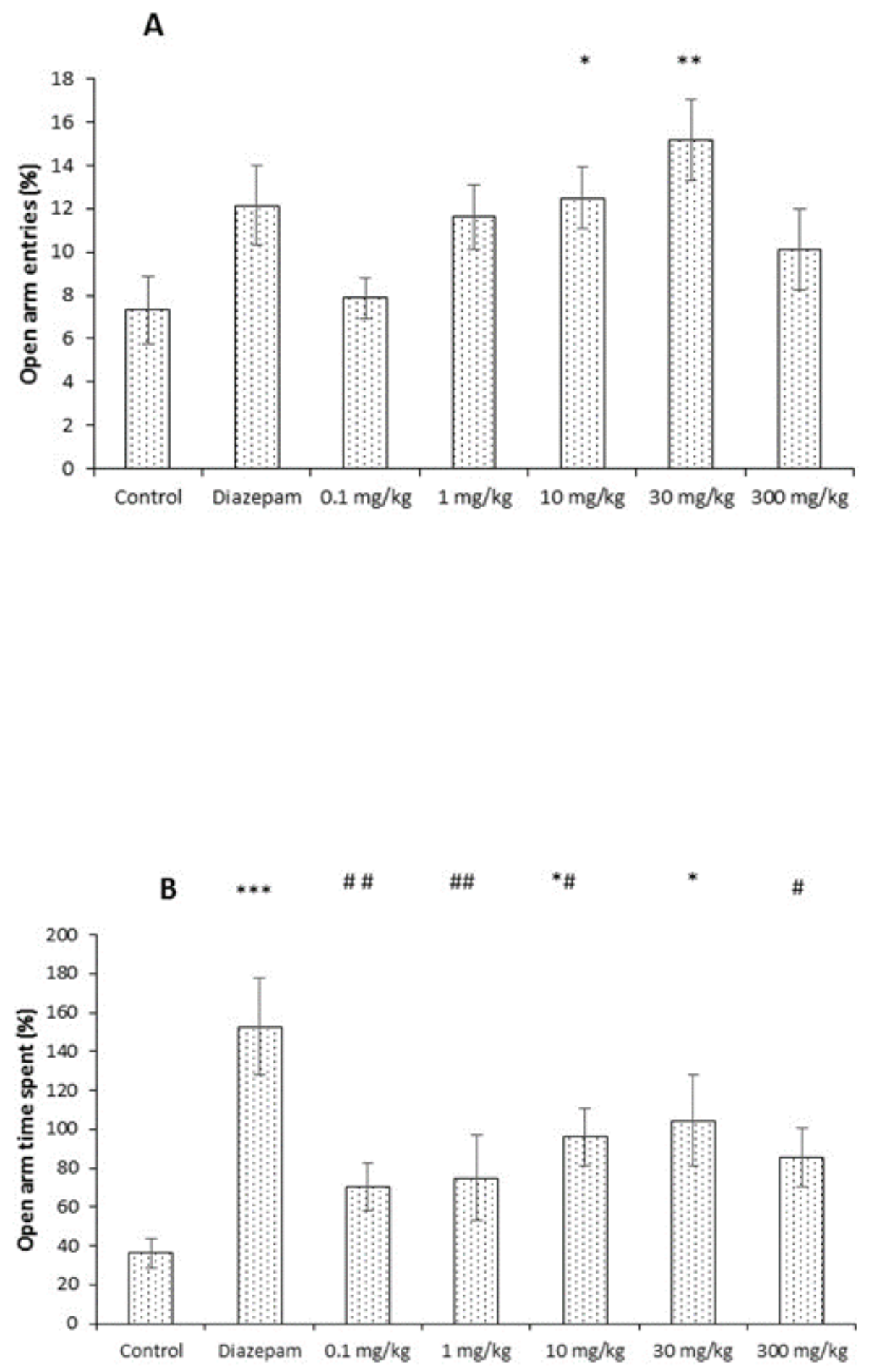

Figure 1

Effect of different doses of salicylic acid on the elevated plus maze parameters. Data are presented as mean \pm SEM. Post hoc test: Duncan. A and B show the effect of salicylic acid on open arm entries and open arm time spent. $*: p<0.05, * *: p<0.01$ and $* * *: p<0.001$ compared with control group. $\#: p<0.05$ and \#\#: $p<0.01$ compared with the diazepam group. 

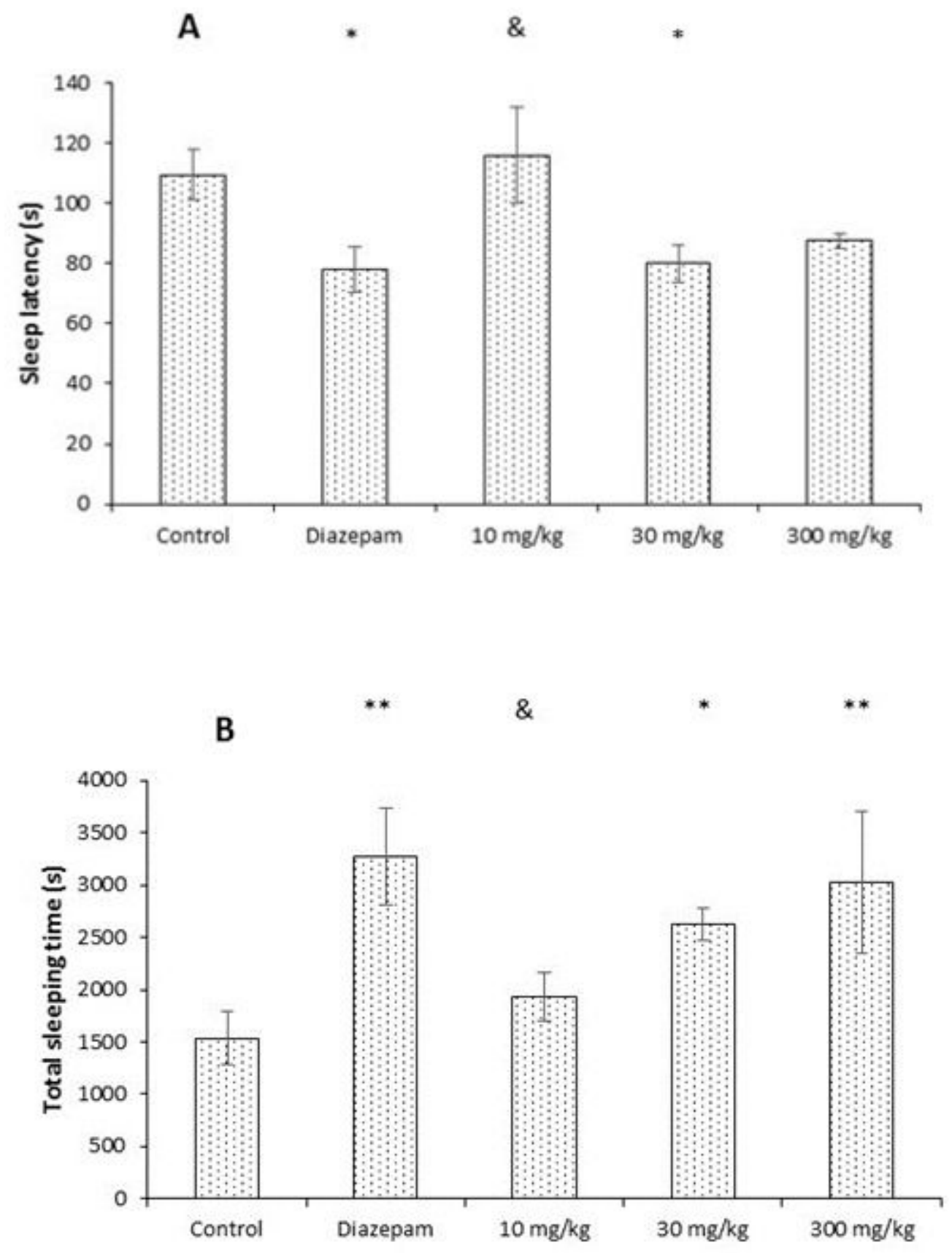

Figure 2

Sedative effects of salicylic acid on ketamine-induced hypnosis. Data are presented as mean \pm SEM. Post hoc tests: Duncan and LSD. A: Effect of salicylic acid on sleep latency. *: P $<0.05$ compared to control group. \&: $p<0.05$ compared with the diazepam and (SA) $30 \mathrm{mg} / \mathrm{kg}$ groups. B: Effect of salicylic acid on total sleeping time. *: $P<0.05, * *: p<0.01$ compared with control group. \&: $p<0.05$ compared with the diazepam and (SA) $300 \mathrm{mg} / \mathrm{kg}$ groups. 


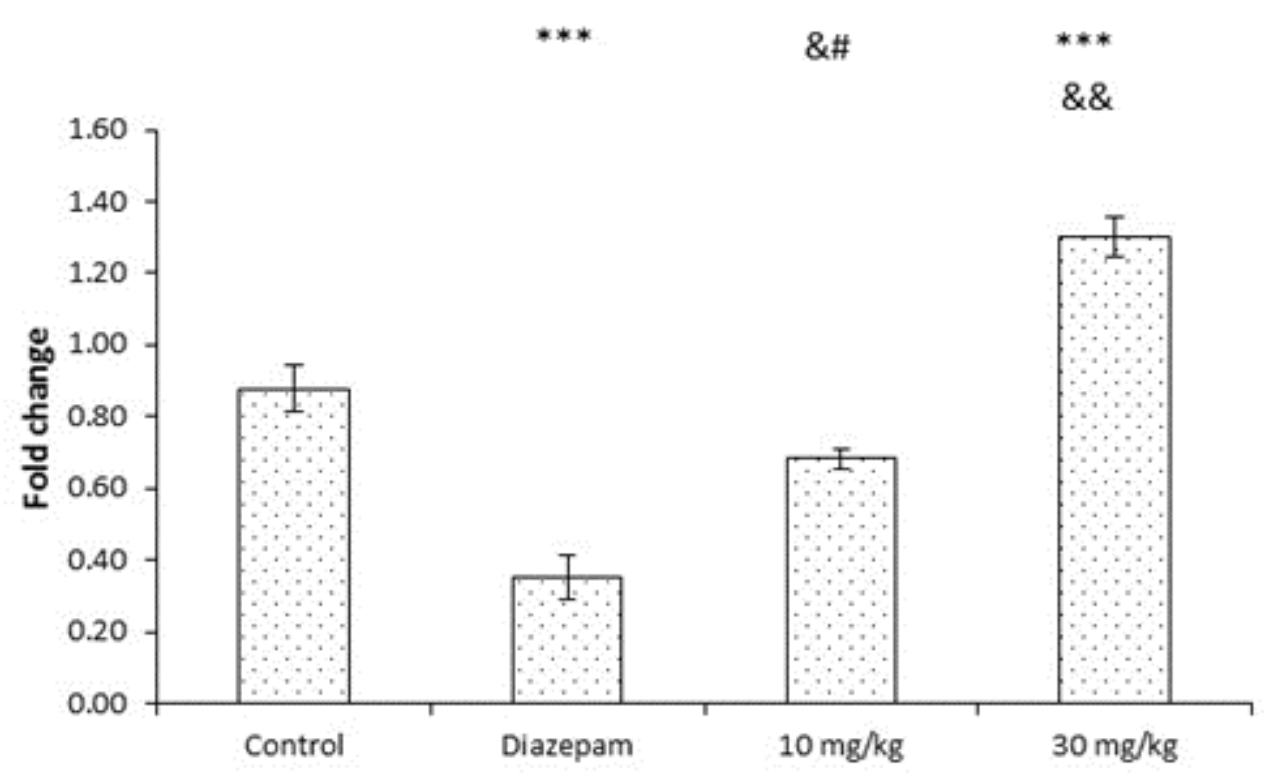

Figure 3

Effect of salicylic acid on hippocampal GAD67 gene expression. Data are presented as mean \pm SEM. Post hoc test: Duncan. ${ }^{* *}: p<0.001$ compared with control group. \&: $p<0.01$ and \&\&: $p<0.001$ compared with the diazepam group. \#: $p<0.001$ compared with the group received $30 \mathrm{mg} / \mathrm{kg}$ of salicylic acid. 